\title{
CUTANEOUS RESPONSIVENESS IN PRIMARY SOMATOSENSORY (S-I) HINDPAW CORTEX BEFORE AND AFTER PARTIAL HINDPAW DEAFFERENTATION IN ADULT RATS $^{1}$
}

\author{
J. T. WALL ${ }^{2}$ AND C. G. CUSICK
}

Department of Psychology, Vanderbilt University, Nashville, Tennessee 37240

Received July 6, 1983; Revised November 23, 1983; Accepted January 4, 1984

\begin{abstract}
The hindpaw of the rat is normally innervated by the sciatic and saphenous nerves. In the present studies, the hindpaws of adult rats were partially deafferented by transection of the sciatic nerve for variable periods of time. The organization of the hindpaw representation in primary somatosensory (S-I) cortex was then studied with neurophysiological mapping techniques and compared to the organization seen in normal rats. The objective was to determine whether cutaneous responsiveness was recovered in the cortical area which lost normal cutaneous inputs from the sciatic nerve, and, if recovery occurred, to characterize the time course and spatial extent of this recovery.

Normal rats were found to have a topographically organized representation of the hindpaw in SI cortex. As determined by nerve recording and cortical mapping, approximately $85 \%$ of this representation is responsive to cutaneous inputs from the sciatic nerve, while the remaining $15 \%$ is responsive to inputs from the saphenous nerve. Following transection of the sciatic nerve, all hindpaw skin regions normally innervated by the sciatic nerve remained denervated. In cortex, the representation of cutaneous inputs from the saphenous nerve expanded into parts of the hindpaw region normally representing sciatic inputs and occupied an area about 3 times larger than the saphenous representation in normal rats. This expansion was initially observed 1 to 2 days after transection and was stably maintained with longer deafferentation times. However, even after chronic deafferentation of up to 5 months, this enlarged saphenous representation was still only half the size of the normal hindpaw representation in normal rats.

These findings suggest that cortical representations of deafferented skin can become activated by substitute cutaneous inputs. The rapid time course for substitution suggests these changes are due to functional modifications in normally existing connections. With the deafferentation conditions used in the present study, input substitution was limited to only parts of the deprived cortex. A hypothesis is presented which suggests these changes are due to adjustments in the dominance of saphenous and sciatic inputs to specific regions of cortex.
\end{abstract}

Primary somatosensory cortex normally contains a topographically organized representation of cutaneous inputs from the contralateral surface of the body. Recent studies in adult mammals indicate normal cortical organization is changed when skin regions are deafferented by transection of peripheral nerves or dorsal roots (Kalaska and Pomeranz, 1979; Franck, 1980; Franck et al., 1980; Kelahan and Doetsch, 1981; Schoppmann et al.,

\footnotetext{
${ }^{1}$ We would like to thank Dr. Jon H. Kaas for helpful discussions during this research and Dr. James A. McKanna for the use of his Apple Computer and Bioquant II System. This research was supported by Grant BNS-8205745 from the National Science Foundation and Grant NS-16446 from the National Institutes of Health.

${ }^{2}$ To whom correspondence should be addressed.
}

1981; Rasmusson, 1982; Merzenich et al., 1983a; also see Kaas et al., 1983 for review). In particular, cortical neurons can become responsive to cutaneous inputs which are outside their normal skin fields if these fields are deafferented. Due to this change, the cortical representations of skin regions which are near, but outside, deafferented zones become larger. Most reports have dealt with chronic deafferentation, but there is also evidence that cortical effects initially become apparent within the first several hours after nerve blockade or injury (Metzler and Marks, 1979; Kelahan and Doetsch, 1981; Merzenich et al., 1983b). This suggests that connections between skin and cortex can undergo rapid alterations in organization when normal inputs are disrupted.

Two issues remain unclear from these studies. First, 
how extensive is cortical reorganization after deafferentation? Do all cortical regions which lose their normal inputs eventually recover alternate cutaneous inputs, or are some regions unable to recover cutaneous responsiveness? This issue is important for understanding spatial limitations of recovery of cutaneous responsiveness after injury. Second, what is the time course for cortical reorganization? What extent of cortical change occurs soon after injury and what extent occurs more progressively with longer periods of deafferentation? This issue is important for understanding mechanisms underlying cortical changes.

The present experiments examined these issues in the hindpaw representation of the primary somatosensory (S-I) cortex of adult rats. In initial experiments, the innervation of the hindpaw was defined in normal rats with nerve recordings of the sciatic and saphenous nerves. From these studies it was apparent that transection of the sciatic nerve would deafferent a large portion of the hindpaw skin. Cortical mapping procedures were then used to describe the location, topographical organization, and areal size of the hindpaw representation in normal adult rats and adult rats whose hindpaws had been deafferented for various lengths of time by transection of the sciatic nerve. From these data, it was possible to assess directly the spatial and temporal parameters for recovery of cutaneous responsiveness in parts of the hindpaw representation which had lost their normal inputs from the sciatic nerve.

\section{Materials and Methods}

Studies were carried out on adult ( $>90$ days old) Sprague-Dawley rats of both sexes. In one set of experiments, the innervation of the hindpaw was studied in normal rats. The remaining experiments involved mapping the hindpaw representation in the S-I cortex of normal and deafferented rats.

\section{Sciatic and saphenous nerve recordings in normal rats}

Innervation to the hindpaw was studied in nerve recording experiments in which receptive field territories were determined for the saphenous $(N=4)$, sciatic $(N$ $=3)$, or both $(N=3)$ nerves. These studies were initiated to provide a basis for selecting an appropriate deafferentation procedure and for describing the deafferented skin region. As described below, after seeing the results of these studies, it became apparent that this information could also be used to identify the source of input for cortical neurons with receptive fields on different parts of the hindpaw.

Nerve mapping procedures. Animals were anesthetized with ketamine hydrochloride ( 50 to $75 \mathrm{mg} / \mathrm{kg}$, i.m.) and one hindlimb was mounted in a position which allowed access to the hindpaw and the nerve being studied. The nerve was cut at thigh levels and an attempt was made to define a receptive field from multiple fiber activity while the whole nerve was hung over a hook electrode. The epineurium was then split and all fascicles were recorded individually. Finally, each fascicle was dissected and recordings were made from small strands of fibers. The portion of the nerve which had been recorded was then trimmed off and the above procedure was repeated until all branches of the nerve had been sampled repeatedly down to the ankle. In some experiments, the hook electrode was replaced with a tungsten microelectrode (1 megohm measured at $1 \mathrm{kHz}$ ) which was used to impale a whole nerve or fascicle through its cut end. This procedure provided good multiple and single fiber recording with less damage than was possible with dissection of fascicles. In general, but especially for the sciatic nerve, the quality of the recordings improved as the recording location moved distally on the nerve. Near the ankle the branches of both nerves are small, and recordings from whole fascicles gave very brisk responses which allowed clear delineation of receptive field boundaries. Receptive fields were determined with tactile stimuli similar to those used for cortical studies and were recorded on detailed line drawings of the hindpaw. In rats in which recordings were made from both nerves, specific attempts were made to delineate overlap in the innervation fields of the two nerves. In these cases, tactile stimuli were delivered while viewing the skin with a microscope, and the edges of innervation territories were marked on the hindpaw skin as well as on the line drawings to allow direct comparison of borders.

\section{Cortical mapping of the hindpaw representation in normal and deafferented rats}

The representations of the hindpaw, hindlimb, trunk, and forelimb were mapped in 17 normal rats to establish the relative location of the hindpaw representation with respect to adjacent cortical representations and to study the topographical organization of the hindpaw representation. Cortex devoted to the hindpaw was completely mapped in high detail in 10 of these animals to allow measures of the size of the normal hindpaw representation. The cortical representation of the hindpaw and adjacent skin regions was completely mapped in high detail in 19 rats which had been deafferented for periods ranging from 1 to 156 days. Measurements were also made of the size of the hindpaw representation in all deafferented rats.

Cortical mapping procedures. Animals were initially anesthetized with ketamine hydrochloride (50 to $75 \mathrm{mg}$ / $\mathrm{kg}, \mathrm{i} . \mathrm{m}$.) and maintained with supplemental injections as needed. The ear canals and scalp were treated with local anesthetic ( $5 \%$ xylocaine), the head was fixed in a stereotaxic frame, and the animal was positioned on a thermostatically controlled water pad which maintained rectal temperature at $37^{\circ} \mathrm{C}$. A craniotomy was made over the dorsal surface of one hemisphere, and a cylinder was mounted on the skull around the craniotomy. The dura was then reflected, the cylinder was filled with silicone fluid, and a highly magnified $(\times 25$ to $\times 30)$ photograph was made of the cortical surface.

A gridlike array of penetrations was spaced across the more medial extent of the S-I cortex. Penetrations were made with tungsten microelectrodes (1.0 to 1.5 megohms measured at $1 \mathrm{kHz}$ ) which were angled perpendicular to the cortical surface. The microelectrode and cortical surface were viewed through a dissecting microscope $(x$ 200 ), and the point of entry for each penetration was 
carefully marked on the brain photograph. Depending on the arrangement of the surface vasculature, efforts were made to space penetrations 150 to $300 \mu \mathrm{m}$ apart, with a typical experiment consisting of approximately 60 to 110 penetrations across the hindpaw and adjacent cortical regions. While using conventional techniques for recording neural activity, the microelectrode was advanced into the cortex until multiple unit responses to brushing of the skin and hairs were maximized on an audiomonitor. The most brisk responses were usually recorded at microdrive readings of 500 to $800 \mu \mathrm{m}$ below the cortical surface in both normal and deafferented rats. Cutaneous receptive fields were defined with tactile stimuli which were delivered to the skin and hairs with handheld probes, brushes, or bristles. Regions of skin from which responses were evoked were marked on drawings made from photographs of the hindpaw and body surface. In addition to responses to cutaneous stimuli, responses observed to harder tapping of the body surface were noted. In penetrations where no evoked responses were observed, efforts were made to stimulate vigorously wide regions of the body surface as the electrode was advanced to depths well below (1000 to $1300 \mu \mathrm{m}$ ) the normally responsive depths and, as the electrode was withdrawn, to the cortical surface.

To analyze the mapping results, receptive field loca tions were related to each penetration site in the cortex. A two-dimensional representation of the hindpaw and adjacent skin surface was then reconstructed by delimiting cortical regions with receptive fields at identified skin locations. Borders between cortical representations of different body parts were established midway between adjacent penetrations which had receptive fields at different skin locations. If the receptive field of a penetration equally straddled skin parts which were being distinguished, the border separating the involved cortical representations was placed at the penetration position. Borders between cutaneous representations and adjacent cortical areas not responsive to cutaneous stimuli were established midway between responsive and adjacent nonresponsive penetration locations. Using these borders, the size of the cortical representation of the hindpaw or parts of the hindpaw was measured with a computerized planimeter system (Bioquant II, Apple Computer). These procedures provided a simple and repeatable way of defining the spatial distribution and size of cortical regions which were responsive to inputs from defined skin locations.

All mapping studies were done with two investigators, one to move the electrode and record the penetration location on the brain photograph and a second to define and record receptive fields. In all experiments, the investigator mapping receptive fields did not see the brain photograph and did not have direct knowledge of the location of the electrode during the course of the experiment. Precautions were also taken to prevent the investigator who mapped receptive fields from knowing which experimental group the animal was from. Maintenance of this blind procedure was not always possible since longer term sciatic denervation resulted in obvious atrophy in the mass of the hindlimb, but it was effectively used for the animals with shorter term denervations.
Denervation procedures. For transection of the sciatic nerve, rats were lightly anesthetized with either ketamine hydrochloride or ether. Local anesthetic (5\% xylocaine) was applied to the lateral surface of the thigh, and an incision was made from the sciatic notch to the knee. Under microscopic view, the sciatic nerve was isolated from surrounding muscle, ligated two or three times just distal to the sciatic notch, and transected distal to the ligatures. To prevent regeneration, efforts were made to remove as much of the distal stump as possible down to the knee, and in some animals the proximal stump and ligatures were embedded in dental acrylic or histoacryl. In other animals the nerve was sectioned near the knee, the epineurium of the proximal stump was rolled back to the sciatic notch, and the exposed fascicles of the nerve were cut near the notch. The epineurium was subsequently rolled back out and knotted with ligatures. The skin incision was closed with suture and treated topically with an antibiotic. Deafferented animals were housed in cages with smooth plastic floors and adequate litter to prevent further injury to the hindpaw.

\section{Results}

\section{Normal adult rats}

Innervation of the hindpaw skin. Innervation to the skin on the hindpaw is supplied by the sciatic and saphenous nerves. The cutaneous distribution of sensory fibers in both nerves was determined directly with nerve recordings, and the innervation territories defined from two representative experiments in which both nerves were recorded are shown in Figure 1. As can be seen, the sciatic nerve innervates the major part of the hindpaw skin. Its territory includes the entire plantar surface (Fig. $1, A$ and $E$ ), the dorsolateral third to half of the hairy foot (Fig. 1, $B, D, F$, and $H$ ), the lateral ankle (Fig. $1, D$ and $H$ ), and a small area of skin on the medial posterior ankle (Fig. 1, $C$ and $G$ ). In contrast, the saphenous nerve innervates a relatively small region of hairy skin extending over dorsal toes 1 to 3 and the dorsomedial foot and ankle (Fig. $1, A$ to $C$ and $E$ to $G$ ).

There appeared to be little overlap in the territories of the saphenous and sciatic nerves on the hindpaw when boundaries of innervation zones were compared in the same animal. For example, the amount of overlap along most of the boundary across hairy skin on the dorsal hindpaw (Fig. 1, $B$ and $F$ ) was $1 \mathrm{~mm}$ or less. This degree of overlap is probably within the error of determining the border, since innervation territories may have interdigitations or small irregularities. There was somewhat more overlap on the dorsal surface of toe 3 which was jointly innervated in the rats shown in Figure 1, but this entire area was innervated by the saphenous nerve in other rats. Borders on toes 1 to 3 and on the medial edge of the hindpaw were near the transition of hairy and nonhairy skin (Fig. $1, A$ and $E$ ). On the skin of the medial ankle there also appeared to be little overlap, although the relative location of the horder varied somewhat (Fig. 1, $C$ and $G$ ).

In summary, the nerve recording experiments indicate that the sciatic and saphenous nerves innervate relatively constant and well defined regions of the hindpaw. 


\section{NORMAL HINDPAW INNERVATION}

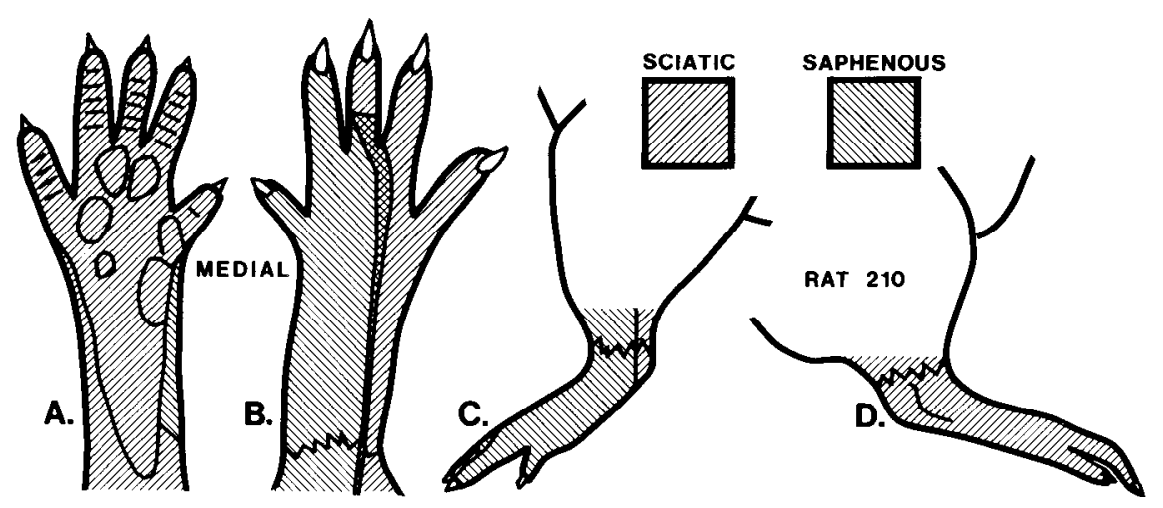

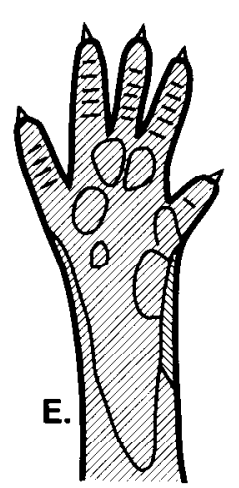

PLANTAR

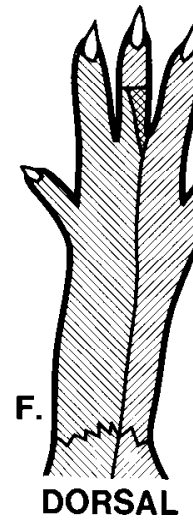

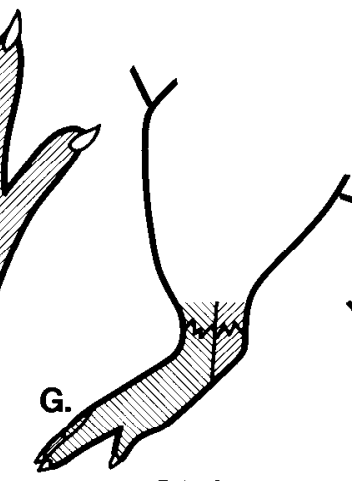

MEDIAL

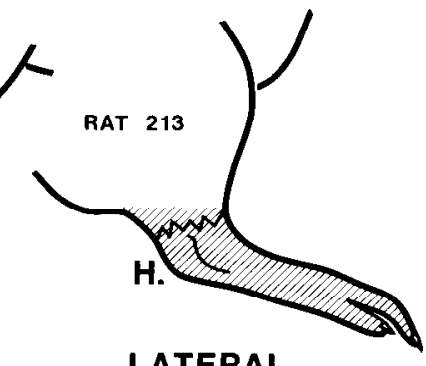

LATERAL

Figure 1. Normal innervation of the hindpaw by the sciatic and saphenous nerves. In this and all subsequent figures "hindpaw" refers to skin areas distal to the hairline at the ankle. $A$ to $D$ show results from one rat in which both nerves were mapped. Skin areas innervated by each nerve as well as areas with overlapping inputs from both nerves are indicated. $E$ to $H$ show results from a second rat to indicate the variability seen for borders. Note that each nerve has a fairly constant innervation territory and there is relatively little overlap of territories.

Since the sciatic nerve innervates most of the hindpaw, its transection clearly deafferents a major fraction of the hindpaw skin. These experiments further indicate that there is little overlap in the innervation territories of these nerves on the hindpaw. Since innervation zones are relatively constant and have little overlap, it is possible to identify the source of innervation for any skin region on the hindpaw by reference to these territories.

Location and topographical organization of the hindpaw representation. The normal location of the hindpaw cortex is indicated in Figure 2, which shows cortical maps from three representative normal rats. As indicated by the stippled region, the hindpaw representation is located in a strip of cortex running mainly in a rostrocaudal direction (Fig. 2, $B$ to $D$ ). It is bounded caudolaterally by representations of the hindlimb and pelvic or abdominal regions of the trunk. Although the representation for the forepaw extends up to or near the rostral border of the hindpaw representation, the remaining medial, rostral, and lateral borders of the hindpaw representation are adjacent to cortex which is not responsive to tactile stimuli. The hindpaw representation thus occupies a rather consistent location in the S-I cortex and can accurately be identified from animal to animal by the tactile responsiveness of its neurons and by its relative position with respect to representations of other body parts.

There is a consistent topographical organization within the hindpaw representation of normal rats. This topography appeared fairly coarse in that receptive fields were relatively large and usually overlapped to some degree at neighboring penetrations. However, with larger movements across the hindpaw representation, it was possible to distinguish systematic shifts in receptive field locations. Representations of both the nonhairy and hairy skin were similarly organized in that distal parts of the hindpaw, for example the toes, were represented rostrally in the hindpaw cortex with more proximal skin on the ankle or heel represented more caudally near the representations of the hindlimb and trunk. This organization is illustrated in Figure 3, which shows receptive fields defined at 17 selected recording locations in or near the hindpaw cortex of a normal adult rat. For each of the four rows of penetrations shown in Figure $3 A$, there is a rough shift in receptive field location from distal to proximal on the hindpaw and hindlimb (Fig. 3, $B$ to $G$ ) as recording position moved from rostral to caudal in cortex. In addition, skin locations on the medial hindpaw are represented laterally, whereas the lateral hindpaw is represented medially in the hindpaw cortex (compare receptive fields for penetrations in Row $A$ versus Row $B$ and Row $C$ versus Row $D$ in Fig. 3). Although representations of hairy and nonhairy plantar skin surfaces on the hindpaw appeared to share the above organizational features, they did not appear to be randomly intermixed. Receptive fields on one type of skin did not extend onto the other type of skin. Nonhairy skin on the plantar surface of the hindpaw is represented 
primarily in the more central and rostral two-thirds of the representation, whereas hairy skin on the dorsal surface and ankle is mainly represented along the lateral, caudal, and medial margins of the representation (Fig. $3 A$ ). Representations for these different types of skin thus appeared to occupy separate cortical regions but were roughly in register with each other topographically. Similar features of normal topographical organization can be observed in the representations of the two rats shown in Figures 4 and 5 and were seen in the other normal animals.

These results indicate that neurons in different parts of the hindpaw cortex normally receive cutaneous inputs from delimited skin areas. The representation of these inputs in normal adult rats is organized in terms of the type of skin from which inputs are derived and the location of these inputs on the hindpaw.

Size measures of representations for hindpaw regions

\section{LOCATION OF HINDPAW REPRESENTATION IN NORMAL ADULT RATS}
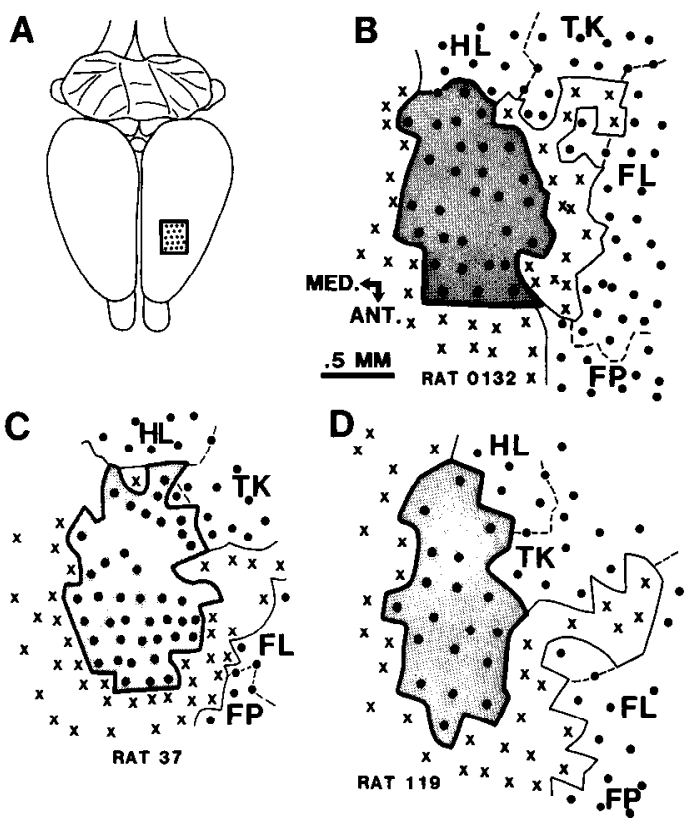

Figure 2. The location of the hindpaw representation in the S-I cortex of normal adult rats. $A$, Dorsal view of the cerebral hemispheres of a rat brain indicating the general location of the hindpaw cortex (boxed region). $B$, The representation of the hindpaw and adjacent body regions as determined for one normal adult rat. Dots indicate locations of penetrations where cortical neurons had cutaneous receptive fields on the indicated body part and $X$ 's indicate penetrations where neurons were not responsive to cutaneous stimulation. The stippled region indicates the hindpaw representation. Parts of neighboring representations of the hindlimb $(H L)$, trunk $(T K)$, forelimb $(F L)$, and forepaw $(F P)$ are also indicated. $C$ and $D$, The representation of the hindpaw and adjacent body regions for two other normal adult rats. Spatial orientation and calibration are as in $B$. Note that the hindpaw representation consistently occupies cortex which is rostromedial to hindlimb and trunk representations and medial to forelimb and forepaw representations. Much of the medial, rostral, and lateral border of the hindpaw representation is adjacent to cortex not responsive to cutaneous stimulation. innervated by the saphenous and sciatic nerves and of the total hindpaw representation. Using the information on innervation territories derived from the nerve recordings, it was possible to define zones of the hindpaw representation which receive inputs from the saphenous or sciatic nerves. For example, by relating the receptive fields defined at individual cortical penetrations to the innervation territories of each nerve, one can identify penetrations as having saphenous or sciatic skin fields. Generally, this sorting procedure allowed unambiguous determination of the distribution and size of the cortical areas receiving inputs from each nerve. Receptive fields on the medial plantar surface of the hindpaw did not extend onto hairy skin. This observation was tested repeatedly whenever plantar fields were encountered by carefully stimulating individual hairs, small groups of hairs, and the hairy skin itself. An additional test done to confirm this observation consisted of holding the plantar skin to attenuate spread of stimulation while vigorously stimulating the hairs and skin within the saphenous innervation territory. Similarly, receptive fields on hairy skin innervated by the saphenous nerve did not extend onto the medial plantar hindpaw. Thus, the border between cortical representations of the two nerves was relatively clear in regions of cortex representing the medial margin of the hindpaw. Fields on the dorsal surface of the foot did not commonly straddle the border between the saphenous and sciatic innervation zones, apparently because the cortical representations for the medial and lateral parts of the dorsal foot are split near the skin border by the intervening representation of the plantar foot (Figs. 3 to 5). Penetrations which were most difficult to relate to nerve input were those with receptive fields on the medial posterior ankle and dorsal toe 3. Due to the variability in the innervation territories of the nerves in these skin regions (Fig. 1), it was sometimes difficult to assign receptive fields at these penetrations to the territory of one nerve. Therefore, these penetrations were defined as being at the boundary between the saphenous and sciatic cortical zones. In instances where fields were not straddling skin borders, cortical boundaries were established halfway between penetrations which had fields at either the sciatic or sciatic or saphenous territories.

The hindpaw representations of four normal adult rats which have been analyzed in this way are shown in Figure 6 . The representation shown in Figure $6 A$ is the same case shown in Figure 5, and comparison of the two figures provides an example of how cortical boundaries for sciatic and saphenous representations were established. The saphenous representation occupied cortex along the lateral margin of the hindpaw representation (Fig. 6A). All penetrations with receptive fields at hairy skin along the medial margin of the hindpaw (Fig. $5 F$ ) were located along the lateral margin of the hindpaw representation (Fig. $5 A$, penetrations indicated by dots within the hatched region). In contrast, all other penetrations had receptive fields located outside the saphenous innervation territory (Fig. 5, $B$ to $E$ ). Comparison of Figure $6 B$ to Figure 3 provides a second example of how boundaries were established between cortical regions representing saphenous and sciatic inputs.

The representations of saphenous and sciatic skin 


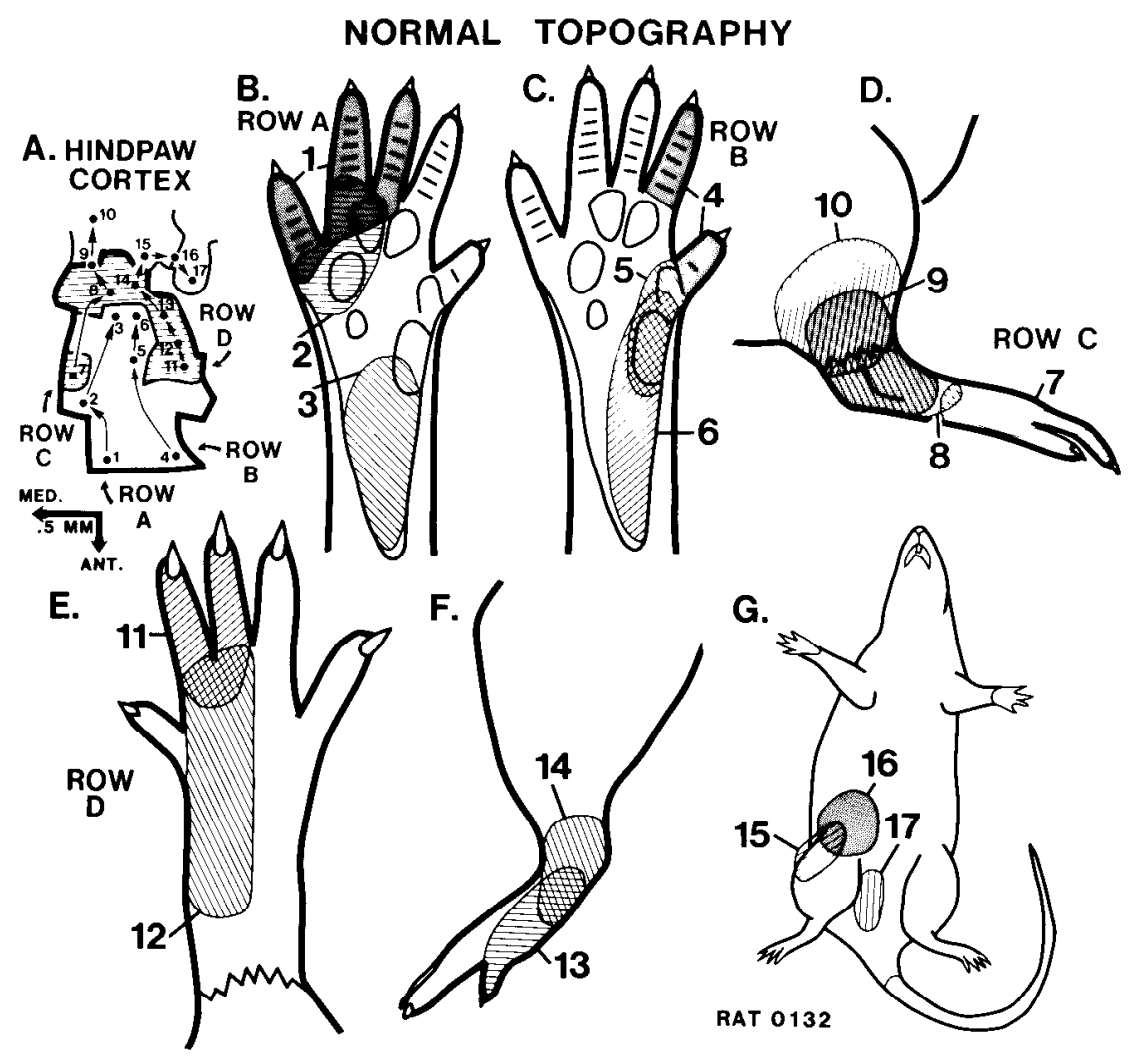

Figure 3. Normal topographical organization of the hindpaw representation. $A$, The hindpaw representation (heavy border) and adjacent representations of the hindlimb and trunk in a normal adult rat. Representations of hairy (hatching) and nonhairy plantar (no hatching) surfaces of the hindpaw are indicated within the hindpaw representation. Dots indicate locations of some of the recording sites in this experiment. Four anterior-to-posterior rows of recording sites are indicated (Rows $A$ to $D$ ). $B$, Receptive fields defined on the lateral plantar surface of the hindpaw at recording locations 1 to 3 of $R o w A$. $C$, Receptive fields defined on the medial plantar skin at recording locations 4 to 6 of Row $B$. $D$, Receptive fields defined on the hairy skin of the lateral hindpaw and hindlimb at recording locations 7 to 10 of Row $C$. $E$ to $G$, Receptive fields defined on hairy skin of the medial hindpaw, hindlimb, and trunk at recording locations 11 to 17 of Row $D$. Note that: (1) for each row, receptive fields shift proximally as recording sites shift posteriorly; (2) medial surfaces of the hindpaw are represented laterally in cortex whereas lateral surfaces are located medially in cortex; and (3) hairy skin on the hindpaw is largely represented posteriorly near the representations of hairy skin on the hindlimb and trunk.

regions seen in Figure 6, which are representative of the other normal rats, suggest the following observations. (1) The cortical representation of saphenous skin is located along the lateral margin of the hindpaw representation and sometimes appears as more than one small area of cortex. The representation for skin innervated by the sciatic nerve occupies cortex located medial and rostral to the saphenous representation. (2) The representation of sciatic skin comprises the major fraction of the total hindpaw representation, whereas the saphenous cortical space is only a small component of this representation.

The size of the cortical area representing the entire hindpaw was measured with a planimeter from maps similar to those shown in Figures 2 to 6 . The mean area for the hindpaw representation for 10 normal adult rats was $0.94 \mathrm{~mm}^{2}$ (Fig. 7). Measures of the representations for sciatic and saphenous inputs indicate the sciatic representation occupies approximately $85 \%$ of the total hindpaw representation with the saphenous representation comprising the remaining $15 \%$ (Fig. 7).

\section{Adult rats after transection of the sciatic nerve}

Innervation of the hindpaw. The surviving innervation to the hindpaws of deafferented rats was assessed by examining the locations of all cortical receptive fields on the hindpaw and by constructing a composite of the skin area covered by these fields in each animal. Receptive field composites from three representative rats are shown in Figure $8, A$ to $C$. It was clear that saphenous inputs survived deafferentation since approximately $95 \%$ of all the receptive fields seen in deafferented rats appeared to be entirely contained within the skin territory normally innervated by the saphenous nerve. The remaining $5 \%$ of the fields appeared to extend somewhat beyond the expected territory of the saphenous nerve. Even in these instances, however, the center of the field and most of the field area was contained within the saphenous nerve tcrritory (Fig. $8 D$ ). No receptive fields extending onto the plantar foot were found in denervated rats. Receptive fields which appeared to extend beyond the saphenous skin were observed as early as 1 to 2 days after deaffer- 
entation. This suggests that some of these fields can be accounted for by minor variation in the innervation territory of the saphenous nerve or by small errors in the definition of receptive fields.

Dissection of the denervated hindlimb after cortical mapping showed that the sciatic nerves had not regenerated back to the hindpaw since most nerve stumps clearly did not extend beyond midthigh levels. It was more difficult to eliminate completely the possibility that small numbers of fibers managed to reach the surrounding thigh muscles, since neuromas sometimes blended into scar tissue formed in these muscles. However, it was clear that the sciatic nerve had not reinnervated any of its normal skin territory distal to the knee and remained completely or nearly completely contained within neuromas.

Thus, there was no substantial recovery of cortical representation for skin areas innervated by the sciatic nerve with deafferentation of up to 5 months. The hindpaw cortex essentially represented only skin areas of the hindpaw normally innervated by the saphenous nerve. These findings suggest low threshold mechanoreceptor

\section{NORMAL TOPOGRAPHY}

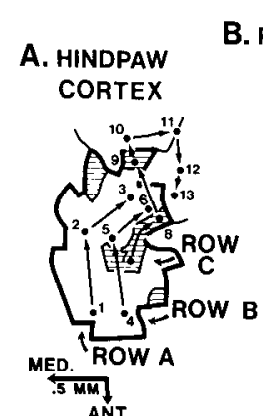

ANT.

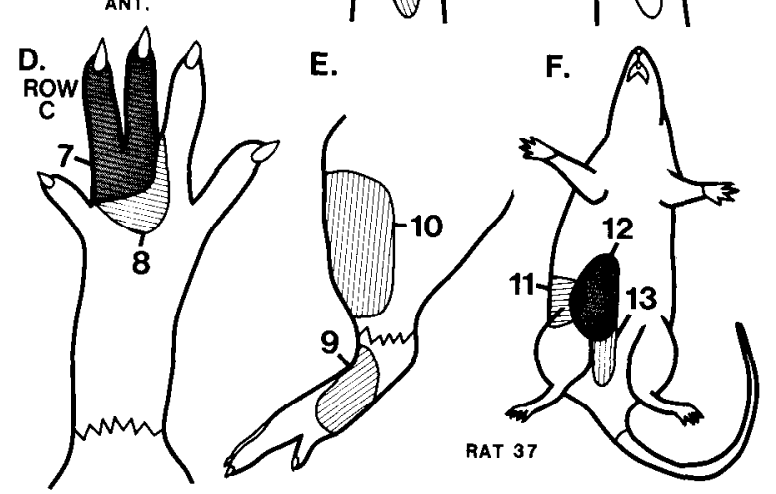

Figure 4. Topographical organization of the hindpaw representation. $A$, The hindpaw rcpresentation (heavy border) and adjacent representations of the hindlimb and trunk in a normal adult rat. Representations of hairy (hatching) and nonhairy (no hatching) surfaces of the hindpaw are indicated. The locations of some of the recording sites in this experiment are also shown (Rows $A$ to $C$ ). $B$, Receptive fields for penetrations 1 to 3 in Row $A$. $C$, Receptive fields for penetrations 4 to 6 in Row $B$. $D$ to $F$, Receptive fields for penetrations 7 to 13 in $R o w C$. Although the representation of hairy skin on the hindpaw appeared less continuous in this rat, the overall topographical organization here is similar to the organization seen in Figure 3.

\section{NORMAL TOPOGRAPHY}
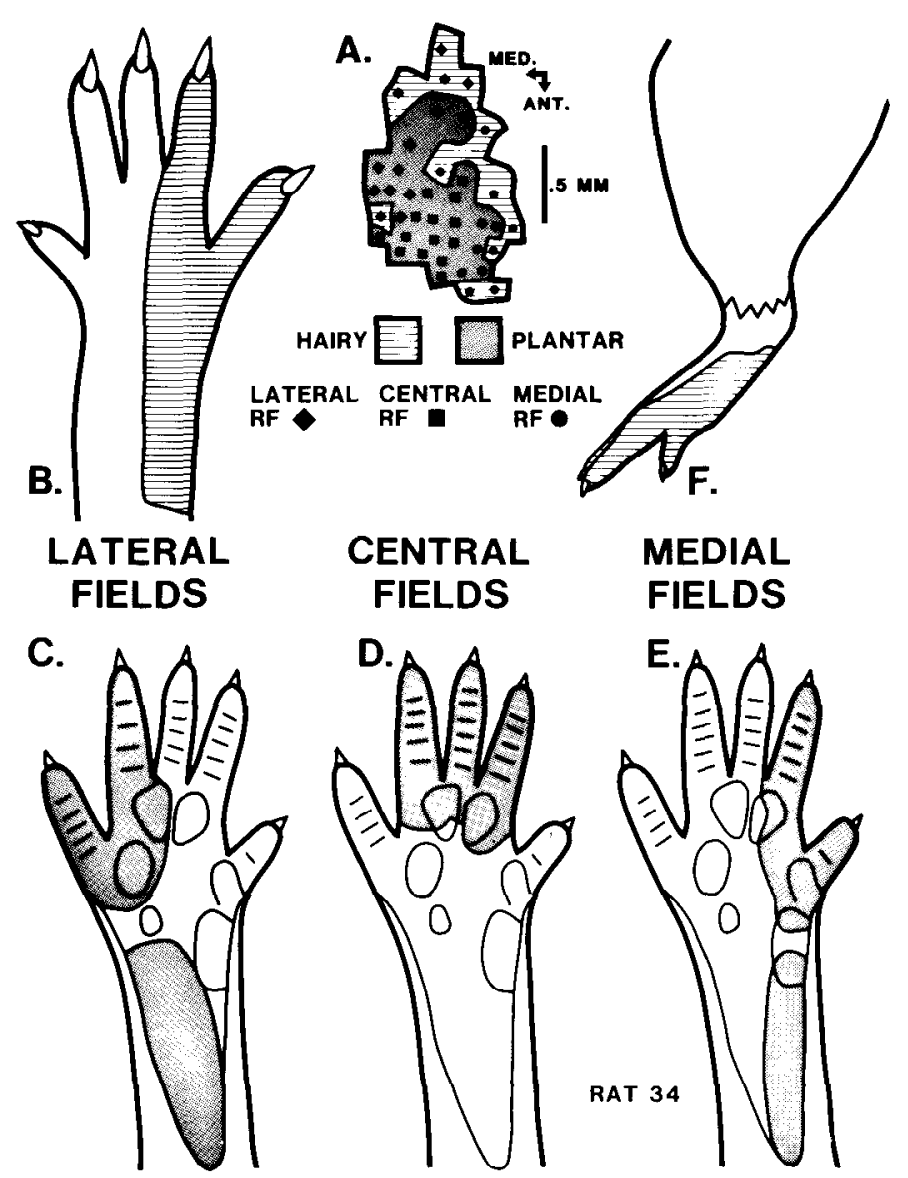

Figure 5. Topographical organization within the hindpaw representation of a normal adult rat. $A$, The hindpaw representation of a normal rat. Cortical areas where recording sites had receptive fields (RFs) on hairy (hatching) or nonhairy plantar (stippling) skin are indicated. Symbols show locations of all recording sites in hindpaw cortex. Sites with receptive fields on

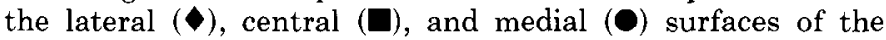
hindpaw are distinguished. $B$, Composite skin area encompassing RFs for all penetrations representing hairy skin on the lateral hindpaw ( $\$$, hatching in $A$ ). $C$, Composite skin area for penetrations representing plantar skin on the lateral hindpaw ( , stippling in $A$ ). $D$, Composite skin area for penetrations representing plantar skin on the central toes ( $\mathbf{u}$, stippling in $A$ ). $E$, Composite skin area for penetrations representing plantar skin on the medial hindpaw (-, stippling in A). F, Composite skin area for penetrations representing hairy skin on the medial hindpaw (, hatching in $A$ ). In $C$ to $E$ composite RF areas overlap somewhat because adjacent penetrations had RFs on more than one adjacent toe; however, the combination of toes was different. Note that recording sites with fields on the lateral foot surfaces are clustered in more medial parts of the hindpaw representation ( $A$ to $C$ ). In contrast, sites with fields on the medial hindpaw are clustered in lateral locations $(A, E$, and $F)$ with middle parts of the hindpaw represented centrally in the hindpaw representation $(A$ and $D)$.

fibers of the saphenous nerve had not sprouted into the vacated sciatic skin territory to any significant extent.

Location and topographic organization of the hindpaw representation. The location of the hindpaw representa- 


\section{HINDPAW REPRESENTATION IN NORMAL ADULT RATS}
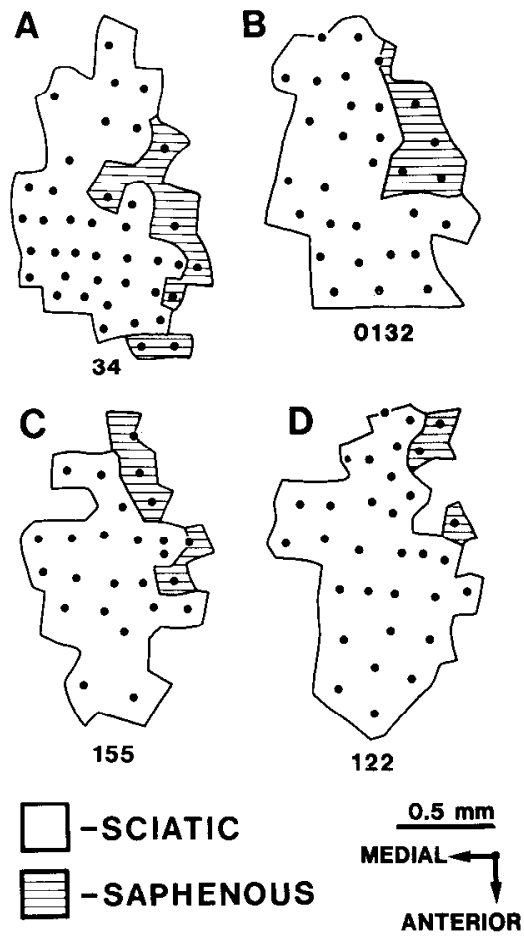

Figure 6. IIindpaw representations from four normal adult rats showing locations of penetrations which had receptive fields at skin areas innervated by the saphenous and sciatic nerves. Inputs from the sciatic nerve occupy most of the medial and rostral parts of the hindpaw cortex, whereas saphenous inputs are found in a relatively small portion of the lateral hindpaw cortex.

tion in the S-I cortex of deafferented rats was similar to that seen in normal adult rats (Figs. 2 and 9). For example, as shown in Figure 9, the hindpaw representation was rostromedial to the representation of the hindlimb and trunk and medial to the representation of the forelimb and forepaw. In addition, most of the medial, rostral, and lateral parts of the hindpaw representation bordered cortex which was unresponsive to tactile stimulation. These identifying features were seen consistently in all deafferented rats regardless of the length of the denervation period (cf. Fig. 9, $A$ to $D$ ). With further inspection, it was also apparent that the location of the hindpaw representation in deafferented rats was similar to that of the representation of saphenous skin in normal rats. For example, in normal rats the representation of the saphenous skin is located along the lateral margin of the hindpaw region and is bordered caudolaterally by the representation of the hindlimb, trunk, and tactilely unresponsive regions (Figs. 2 to 4 , and 6 ). Similar cortical regions are located along the caudolateral border of the hindpaw representation in denervated rats (Fig. 9).

Following deafferentation, there was a coarse topographical organization in the representation of the remaining saphenous inputs which was similar in certain respects to that seen in normal rats. Most notably, receptive field locations shifted from distal to proximal on the hindpaw with anterior to posterior shifts in cortical position (Fig. 10). It was more difficult to demonstrate systematic shifts across the mediolateral axis of the hindpaw representation, primarily because the saphenous skin field is narrow and it was difficult to detect mediolateral shifts in receptive field locations across this skin.

The representations of the medial hindlimb, trunk, forelimb, and forepaw which were near or adjacent to the hindpaw representation did not appear to be disrupted topographically by deafferentation. For example, locations of receptive fields in part of the hindlimb and trunk representations closest to the hindpaw cortex were similar in normal and deafferented rats (Figs. 3, 4, and 10). An exception was that, duc to the level of the sciatic injury in the thigh, the hindlimb representation was mainly limited to inputs from the medial surface of the hindlimb. Receptive fields on the distal lateral hindlimb, usually occupying cortex caudal and medial to the hindpaw representation (Fig. 3), were not seen. The general location of receptive fields in parts of the forelimb and forepaw representation closest to the hindpaw cortex were also comparable in denervated and normal rats. The consequences of the denervation procedure thus appeared to be mainly restricted to cortical regions normally representing the injured inputs.

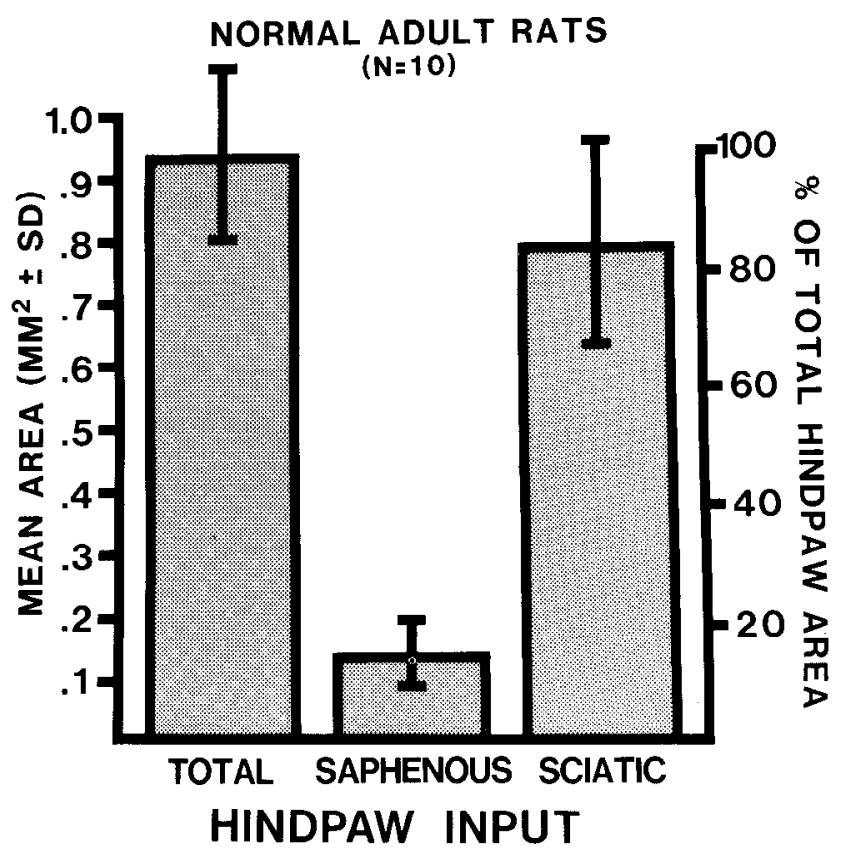

Figure 7. Areas of S-I cortex representing hindpaw inputs in normal adult rats. The left bar shows the mean area (and standard deviation) for the entire hindpaw representation. Areas representing hindpaw inputs from the saphenous and sciatic nerves are shown, respectively, by the center and right bars. The left ordinate indicates area in square millimeters. The right ordinate indicates area as percentage of the entire hindpaw area. Sciatic nerve inputs usually occupy the major portion of the hindpaw representation. 
HINDPAW INNERVATION AFTER SCIATIC SECTION
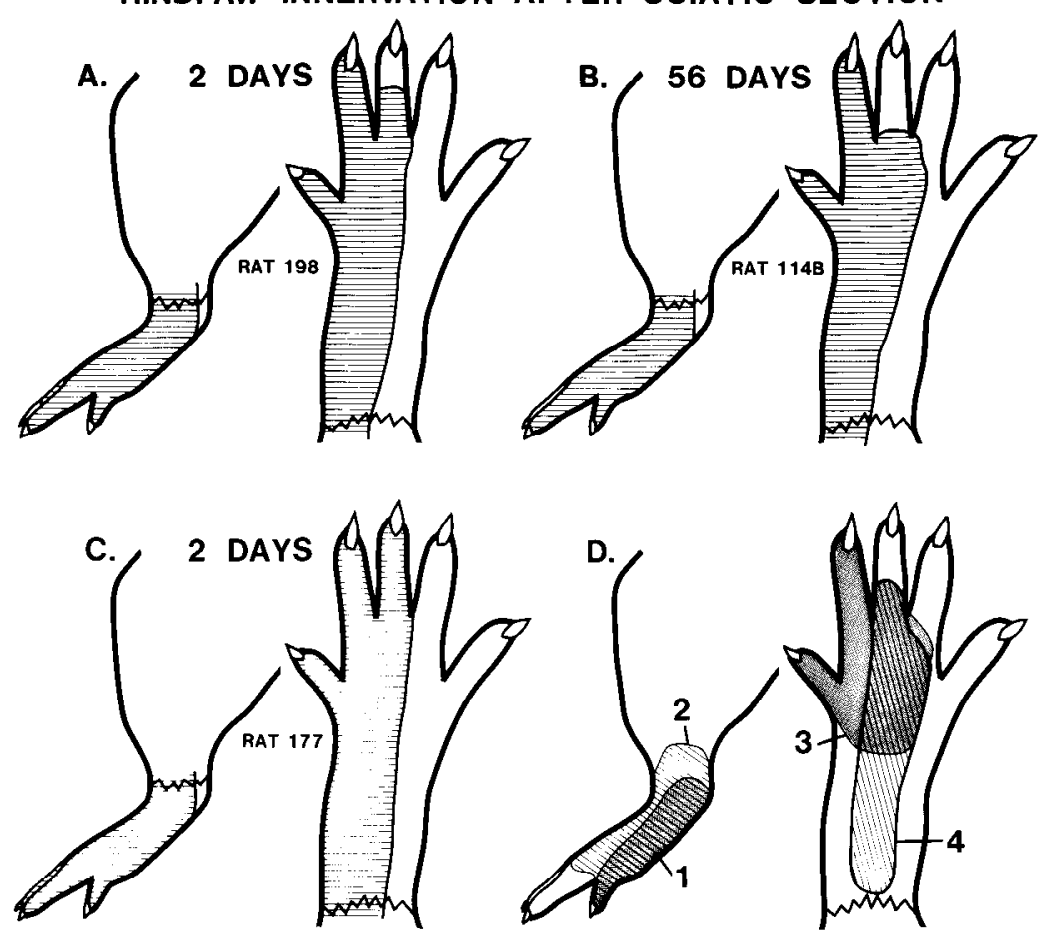

Figure 8. Hindpaw skin areas which activated cortex in deafferented rats. $A$ to $C$, Illustrations of composite receptive field areas for three deafferented rats. $D$, Four examples of receptive fields which appeared to extend outside the normal innervation zone of the saphenous nerve. Note that, even in these examples, most of the field is within the normal saphenous territory (cf. Fig. 1).

\section{HINDPAW REPRESENTATION AFTER SCIATIC SECTION}
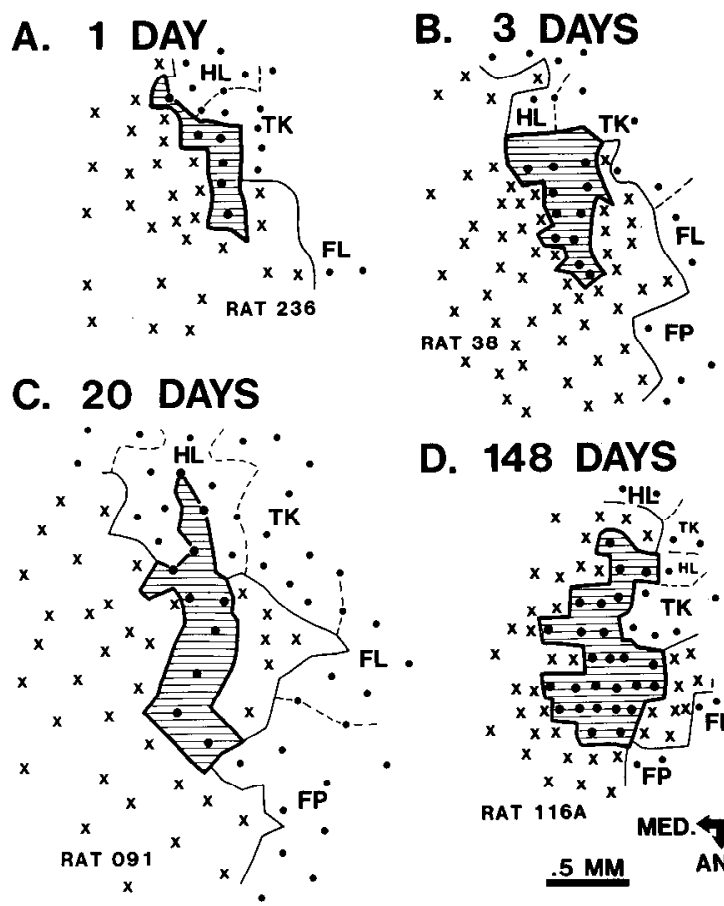

D. 148 DAYS

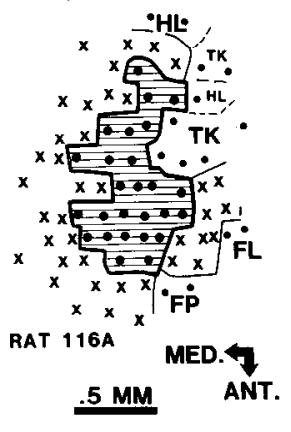

Figure 9. The location of the hindpaw representation (hatched) as seen in four adult rats which had been deafferented
Size measures of the hindpaw representation. Measures of the size of the hindpaw representation were made in all denervated rats, and these data are plotted in Figure $11 A$ as a function of denervation time. Since the hindpaw cortex in denervated rats represented saphenous inputs, area measures of cortex representing saphenous inputs from 10 normal rats have also been included for direct comparison. The data shown in Figure $11 \mathrm{~A}$ indicate that sciatic nerve transection resulted in an enlargement of the saphenous representation. This enlargement occurred in some rats within 1 day of denervation. For example, two of the seven representations measured on day 1 appeared clearly larger than the range of values observed for the saphenous representation in normal rats. Areas of representations 2 or more days after deafferentation also appeared to be above the normal range.

These conclusions are more clearly suggested when the data are expressed as mean areas for groups of animals which had varying deafferentation periods (Fig. 11B). Statistical analyses indicated that the mean area of cortex, representing saphenous inputs in deafferented rats

for 1 day $(A), 3$ days $(B), 20$ days $(C)$, or 148 days $(D)$. All conventions are as for previous figures. Note that the relative location of the hindpaw representation in these deafferented rats is similar to that seen in normal rats (Fig. 2). Spatial calibration and orientation shown in $D$ also apply to $A$ to $C$. 


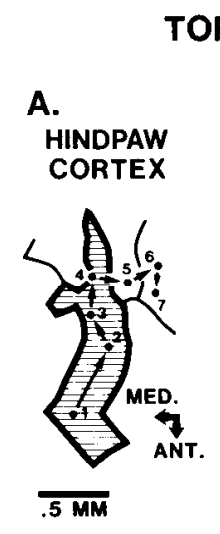

TOPOGRAPHY AFTER SCIATIC SECTION

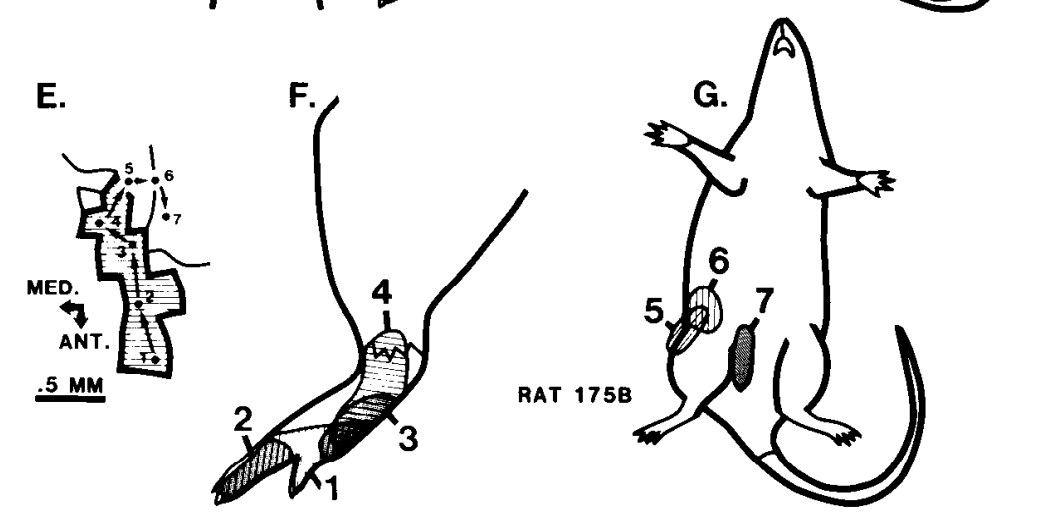

Figure 10. Topographical organization of the hindpaw representation after deafferentation. $A$, The hindpaw representation (hatched area) and adjacent hindlimb and trunk representations in a deafferented rat. Dots ( 1 to 7) indicate locations of recording sites having receptive fields indicated in $B$ to $D$. $E$ to $G$, Similar information from another deafferented rat. Note that the penetrations shown in $A$ and $E$ represent only a proportion of the total penetrations made in these experiments.
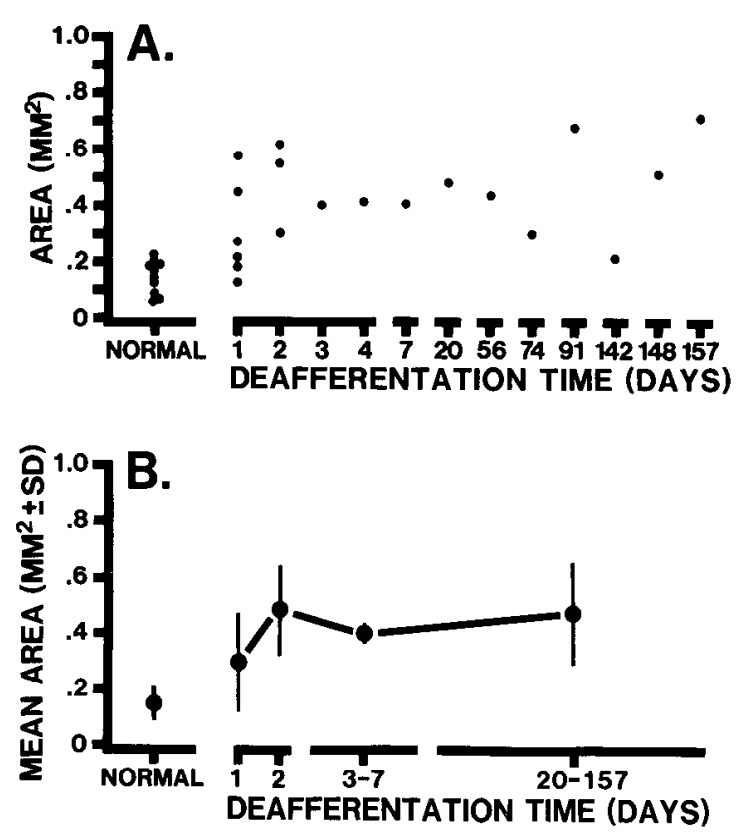

Figure 11. Area measurements of the hindpaw representation in deafferented rats. $A$, Measures of the hindpaw representation taken from 19 individual rats which had been deafferented for the indicated times. Hindpaw inputs in these rats came only from the saphenous nerve. Measurements of the representation considered as a single group $\left(0.41 \mathrm{~mm}^{2}\right)$, was significantly different from the mean area of the saphenous representation in normal rats $\left(0.14 \mathrm{~mm}^{2} ; t(27)=-4.76, p<\right.$ 0.001 ). This change in area occurred rapidly as indicated by a significant difference in the saphenous representation of normal rats and rats denervated 1 day $\left(0.30 \mathrm{~mm}^{2}\right.$; $t(14)=-2.76, p<0.02$ ). In addition, this change was maintained during subsequent months of deafferentation, since the size of the saphenous representation in chronically denervated (20 to 157 days) rats was also significantly different from that of normal rats $(0.47$ $\left.\mathrm{mm}^{2} ; t(15)=-5.19, p<0.001\right)$. Transection of the sciatic nerve in adult rats thus results in about a 3-fold expansion in the size of the cortical representation of saphenous inputs from the hindpaw. This enlargement begins within 1 day of injury and is stably maintained for up to 5 months.

The size measures also showed that the area of cortex representing the hindpaw in denervated rats was smaller

of saphenous nerve inputs taken from 10 normal rats are also shown for comparison. $B$, Data shown in $A$ have been expressed as mean areas for groups of rats which were pooled across the indicated deafferentation periods. Mean area for the saphenous representation in normal adult rats is also shown. 


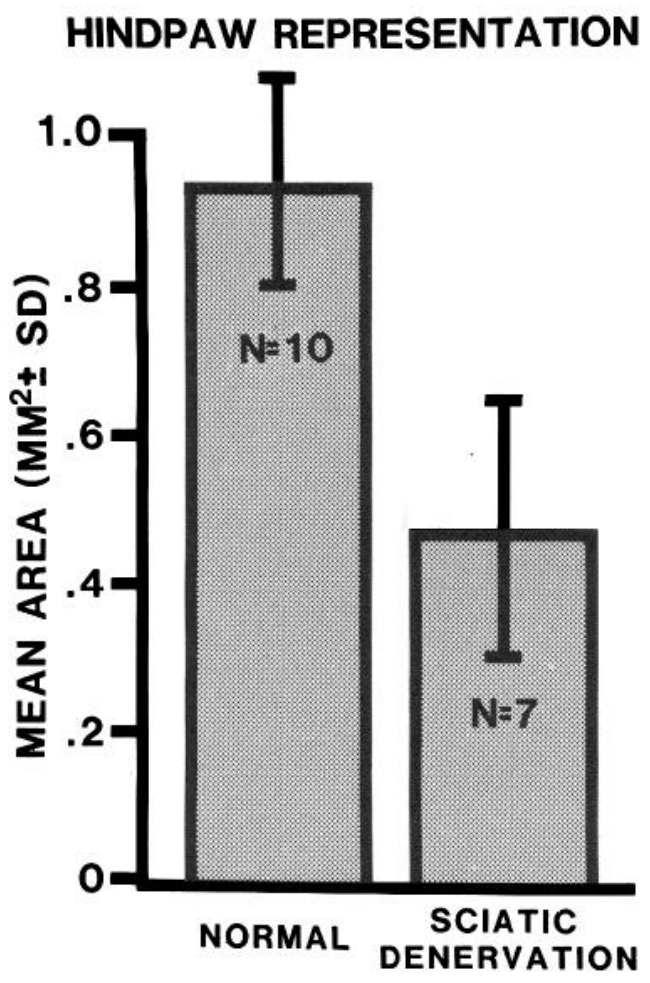

Figure 12. Mean size of the hindpaw representation in normal and chronically deafferented adult rats. The hindpaw area of normal rats reflects combined inputs from the saphenous and sciatic nerves. For denervated rats, all hindpaw inputs are from the saphenous nerve. Note that the enlarged saphenous representation in denervated rats is smaller than the normal hindpaw representation.

than the size of the total hindpaw representation in normal rats (Fig. 12). This observation was statistically confirmed by a comparison of the mean size of the hindpaw representation in chronically denervated $(>20$ days) rats $\left(0.47 \mathrm{~mm}^{2}\right)$ and the mean size of the total hindpaw representation in normal rats $\left(0.94 \mathrm{~mm}^{2} ; t(15)\right.$ $=-5.57, p<0.001)$. These findings indicate that there were limits in the expansion of saphenous inputs and that, even after chronic deafferentation of up to 5 months, some regions of the original hindpaw representation never recovered cutaneous responsiveness. A comparison of Figures 2 and 9 suggests that the cortical regions most likely to remain unresponsive are the medial and rostral poles of the normal hindpaw representation.

\section{Discussion}

\section{Innervation of the hindpaw before and after transection of the sciatic nerve}

As shown by the nerve recording experiments, the hindpaw skin of normal rats is innervated by the sciatic and saphenous nerves. Each nerve has a relatively constant territory, with the sciatic contribution supplying about three-fourths of the hindpaw skin. There is little or no overlap in the innervation regions of low threshold inputs from these nerves.
The normal innervation territories described in this study are in good agreement with previous findings of Devor et al. (1979), who used behavioral testing and nerve recording to define the hindpaw innervation fields of these nerves in rats. The main differences from the present findings appear to be that (1) all of dorsal toe 3 was innervated by the sciatic nerve in their illustrations and (2) the medial edge of the saphenous territory was sometimes shown to include the margin of the plantar skin along the medial foot. These small differences (cf. Fig. 1, present study) may be due to the fact that pinch or pressure stimuli were used to elicit their behavioral responses, and it is likely that the locus of the effective stimulus was only approximately judged in a freely moving rat. Devor et al. (1979) did not show the innervation territories defined with nerve recordings but indicated these territories were similar to those defined in the behavioral studies. Unfortunately, overlap in the innervation fields of these nerves was not described.

Consistent with the present results, other nerve recording studies have demonstrated that the innervation zones of cutaneous nerves can have sharp borders and minor overlap with adjacent innervation zones of other nerves. Burgess et al. (1974) and Horch (1981) found that individual touch domes on cat skin almost always received their innervation from axons of a single peripheral nerve and that sharp borders distinguished domes in the innervation fields of different nerves. Jackson and Diamond (1981) mapped low threshold mechanosensory fields of nerves to back skin of rats and found that innervation territories of identified nerves overlapped "only slightly" and were similar in size and shape from animal to animal. The discrete and autonomous innervation fields of the saphenous and sciatic nerves thus appear like the innervation patterns reported for other cutaneous nerves. The degree of overlap for adjacent nerve fields may vary, however, depending on the particular animal or nerves under study (Kitchell et al., 1982).

After transection of the sciatic nerve, receptive fields of neurons in the hindpaw cortex were almost entirely restricted to skin areas normally innervated by the saphenous nerve. This suggests that, at least as assessed by cortical receptive fields, low threshold inputs of the saphenous nerve did not sprout into the denervated skin to any significant extent. This observation is in agreement with peripheral nerve studies in adult rats (Diamond and Jackson, 1978; Devor et al., 1979; Jackson and Diamond, 1981) and cats (Horch, 1981) which suggest that low threshold mechanoreceptors do not sprout into adjacent, denervated skin regions.

\section{The hindpaw representation in primary somatosensory cortex of normal and deafferented adult rats}

Nor.nal rats. A main goal of this study was to describe the effects of transection of the sciatic nerve on the cutaneous responsiveness of neurons in the hindpaw representation. To do this it was necessary to first characterize the hindpaw representation of normal adult rats. The present findings describe the location and topographical organization of the hindpaw representation and the variability in the size of the cortical area receiv- 
ing inputs from the hindpaw via the sciatic and saphenous nerves.

With respect to the first issue, the present results indicate the hindpaw representation normally occupies a stereotyped position in the S-I cortex. The somatotopic organization of the representations for the hindpaw, hindlimb, trunk, and forelimb seen in the present study is similar to the organization described by others (Woolsey, 1958; Welker, 1971; Hall and Lindholm, 1974; Donoghue et al., 1979; Sapienza et al., 1981).

The present findings suggest that there is a consistent topographical organization within the hindpaw representation. Under the recording conditions of this study, receptive fields on the hindpaw were relatively large, and there was a fair amount of overlap for fields seen at adjacent positions in the hindpaw representation. The internal organization was thus somewhat coarse, but it was clear that hairy and plantar skin surfaces were represented separately. For both plantar and hairy surfaces, distal skin was represented anteriorly in cortex, whereas proximal skin was represented caudally. In addition, skin on the medial hindpaw was represented laterally in cortex, whereas the representation of the lateral hindpaw was more medial. The internal organization of the hindpaw representation has not been described previously in detail, but in each of the previously mentioned studies it was recognized that distal-to-proximal locations on the hindlimb (including the hindpaw) were represented in an anterior to posterior manner in cortex. Welker (1971) also stated that glabrous and hairy skin surfaces of the toes and hindpaw projected to different cortical locations. These observations are entirely consistent with the present findings.

The present results show that the total hindpaw representation occupies approximately $1 \mathrm{~mm}^{2}$ of cortex. The size of the "hindlimb" representation has previously been studied in rats (Welker, 1971; Hall and Lindholm, 1974; Donoghue et al., 1979), but it is difficult to compare these measures with the present hindpaw measures because earlier studies did not distinguish the "hindlimb" (thigh, leg, and hindpaw) from the "hindpaw." The areas reported for the "hindlimb" representation are larger than the present hindpaw area, as would be expected. The dimensions of the hindpaw representation seen in the present study are very similar to those of the cytoarchitectonically defined "foot" region described by Welker (1976).

Since the nerve recording studies indicated that the sciatic and saphenous nerves innervate different parts of the hindpaw, it was possible to characterize further the size and distribution of parts of the hindpaw representation normally activated by low threshold inputs from each nerve. The sciatic nerve normally serves as a dominant source of cutaneous input for about $85 \%$ of the hindpaw representation, whereas inputs from the saphenous nerve activate only $15 \%$ of this representation. Cortex normally receiving sciatic inputs is located in more medial and rostral parts of the hindpaw representation. By comparison, the representation of saphenous inputs is normally found along the lateral or caudolateral margin of the hindpaw cortex. These observations suggest that a major proportion of the cortical neurons in the medial and rostral portions of the hindpaw representation would be deprived of their normal cutaneous inputs after transection of the sciatic nerve.

Deafferented rats. The main findings from the studies of deafferented rats can be summarized as follows.

1. The saphenous representation in deafferented rats occupied an area about 3 times larger than normal. The location of this enlarged representation with respect to other cortical representations was normal. The simplest explanation of this result appears to be that cutaneous inputs from the saphenous nerve activated adjacent cortical regions normally representing sciatic inputs. Thus, following peripheral deafferentation, cortical representations of deafferented skin can become activated by "substitute" cutaneous inputs. The term "substitute" is used to indicate that these inputs were not functionally apparent in normal rats.

2. Following sciatic transection, all substitute cutaneous inputs were from skin areas adjacent to the deafferented hindpaw region. This suggests that peripheral adjacency contributes importantly in determining which cutaneous inputs will become apparent in deprived cortical regions.

3. Expansion of the cortical area representing saphenous inputs was first observed within 1 to 2 days of nerve injury. With longer deafferentation periods of up to 5 months there were no further changes in the size of this representation. This finding suggests that, following some deafferentation conditions, recovery of cutaneous responsiveness can be accounted for entirely by rapidly occurring, functional changes in connections and does not require widespread anatomical modifications.

4. Even though the saphenous representation was enlarged, the area of the hindpaw representation in chronically deafferented rats was still only about half the normal size. Moreover, no other cutaneous inputs appeared to be represented in the region normally representing sciatic inputs. Sciatic transection thus resulted in a net loss of cutaneously responsive cortex. These results indicate that recovery of cutaneous responsiveness is incomplete or limited after some deafferentation injuries.

5. Following sciatic injury, there appeared to be a spatial gradient in recovery across the sciatic cortex. Locations near the saphenous representation apparently had a higher chance for recovery, whereas the medial and rostral margins of the hindpaw representation did not recover cutaneous responsiveness. These observations suggest that limitations in recovery of cutaneous responsiveness may depend partly on how inputs from injured and intact nerves distribute to cortex.

Figure 13 summarizes these findings and indicates one hypothesis for their interpretation. The normal representation of the hindpaw contains regions in which tactile inputs from the sciatic or saphenous nerves predominate (Fig. 13A). After sciatic transection, the saphenous representation still occupies its normal location, but it is larger than normal as a result of increased activation of adjacent parts of the sciatic cortex (Fig. 13B). Even after chronic deafferentation, however, the saphenous representation still remains smaller than the normal hindpaw representation. It seems plausible that the sciatic nerve 

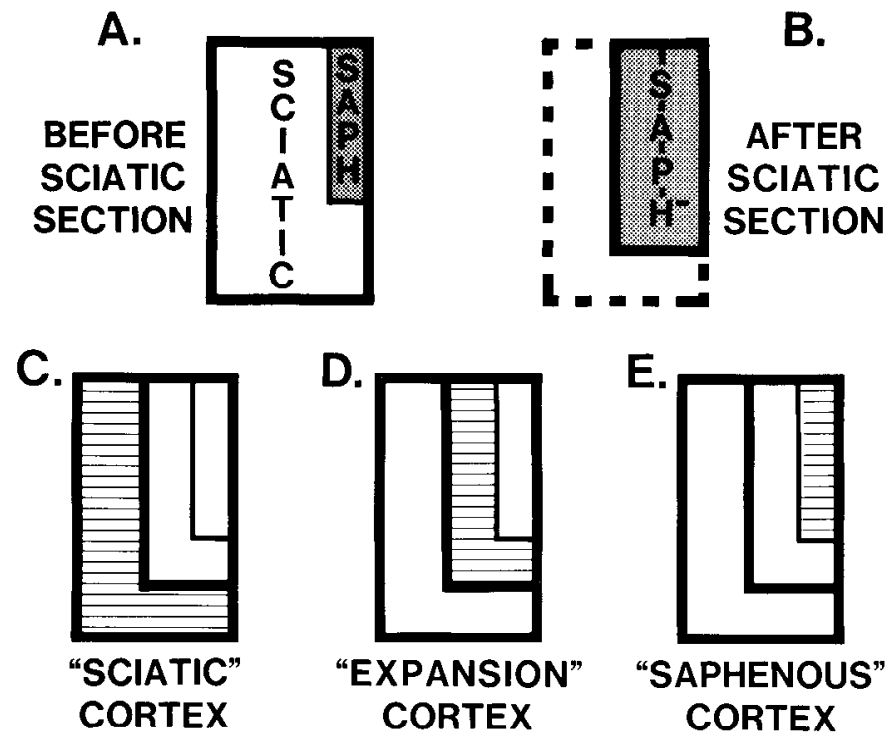

Figure 13. Schematic summary of the results and an interpretation of the present experiments. $A$, In normal adult rats the saphenous and sciatic nerves are distributed to consistent parts of the hindpaw representation. $B$, Following sciatic transection, the saphenous representation maintains its normal cortical location but rapidly enlarges into cortex normally representing sciatic inputs. However, this expanded saphenous representation is smaller than the normal hindpaw representation. The hindpaw representation thus appears to contain a part which is largely or entirely driven by sciatic inputs (crosshatched region in $C$ ), a part which is normally dominated by sciatic inputs but which also receives convergence from saphenous inputs (cross-hatched region in $D$ ), and a part which is largely or entirely driven by saphenous inputs (cross-hatched region in $E$ ). Following sciatic transection, the saphenous representation enlarges into "expansion" cortex but not into "sciatic" cortex.

provides all or most of the cutaneous input to the medialrostral part of the hindpaw representation where cutaneous responsiveness is lost following sciatic transection (Fig. 13C). This part of cortex apparently cannot be accessed by "substitute" cutaneous inputs within the first several months after sciatic injury. The saphenous nerve provides input to the lateral part of the hindpaw representation (Fig. 13E), and this cortex remains responsive to saphenous inputs after sciatic transection. Cortex located between regions normally receiving sciatic or saphenous inputs apparently receives converging inputs from both nerves. However, under normal conditions, this convergence cortex appears to be dominated by the sciatic nerve and is functionally similar to more medial parts of the hindpaw representation in having receptive fields on sciatic skin. If this dominance is disrupted by sciatic transection, saphenous inputs will become dominant input "substitutes," and the "convergence" region becomes a saphenous "expansion" zone (Fig. 13D). The result is a limited enlargement of the normal saphenous representation.

Comparison of the present results to previous findings on the cortical consequences of deafferentation

Table I summarizes previous studies which describe the cortical effects of deafferentation in adult mammals.
As indicated in columns 1 to 4 , previous studies involve several species and have used a variety of procedures to denervate different skin regions. The present results can be related to these studies in the following ways.

1. In agreement with the present results, all earlier studies suggest that cortical neurons can recover cutaneous responsiveness to some degree after disruption of their normal inputs (Table I, column 5). The consistency of this finding strongly implies, first, that adult mammals have a capacity for cortical reorganization after nerve injury and, second, that maintenance of normal organization in primary somatosensory cortex depends on the functional state of peripheral sensory neurons.

2. Consistent with the present results, virtually every previous study has reported that deprived cortex becomes responsive to inputs from skin regions near the deafferented skin (Table I, columns 3 and 6). Substitution of peripherally adjacent inputs thus appears to be a general feature of cortical reorganization after deafferentation.

In contrast to peripheral adjacency, central adjacency appears to be less important for recovery of cutaneous responsiveness. For example, the forepaw and forelimb representations in the rat are near or sometimes adjacent to the hindpaw cortex, yet these representations did not appear to spread into the hindpaw cortex after denervation. Studies of cortical organization after nerve transection in monkeys also suggest that central adjacency, in itself, is not as important as peripheral adjacency. For example, in normal monkeys the representation of the face is adjacent to the representation of median nerve inputs from the hand (Merzenich et al., 1978). Following median nerve transection, deprived parts of the hand representation did not become responsive to face inputs, and the hand-face border remained relatively constant in cortex (Merzenich et al., 1983b). Thus, in both monkeys and rats, central adjacency without a corresponding peripheral adjacency and (presumably) adjacency of input systems up to cortex appears to be relatively unimportant for substitution of cutaneous inputs.

3 . One major goal of the present study was to describe the time course for recovery of cutaneous responsiveness after deafferentation. The main finding is that recovery occurred rapidly and was subsequently maintained at this level following prolonged deafferentation. The time course for recovery of cutaneous responsiveness has not been closely analyzed in previous studies. Earlier investigations (a) studied recovery after either acute or chronic deafferentation, but usually not both (Table I, column 7) and (b) did not attempt to quantify the extent of recovery other than to state, for example, the proportions of small samples of neurons which were responsive after deafferentation. Given these limitations, it is difficult to describe a general pattern for the rate of cortical recovery in these studies. From the studies in which acute effects of deafferentation have been examined it seems that some degree of recovery occurs soon (within several hours to 1 day) after injury. This finding is consistent with the present results in suggesting that cortical changes involve some degree of functional reorganization. Investigations of chronic deafferentation indicate that acute changes become more fully established with time; however, the lack of a quantitative evaluation 


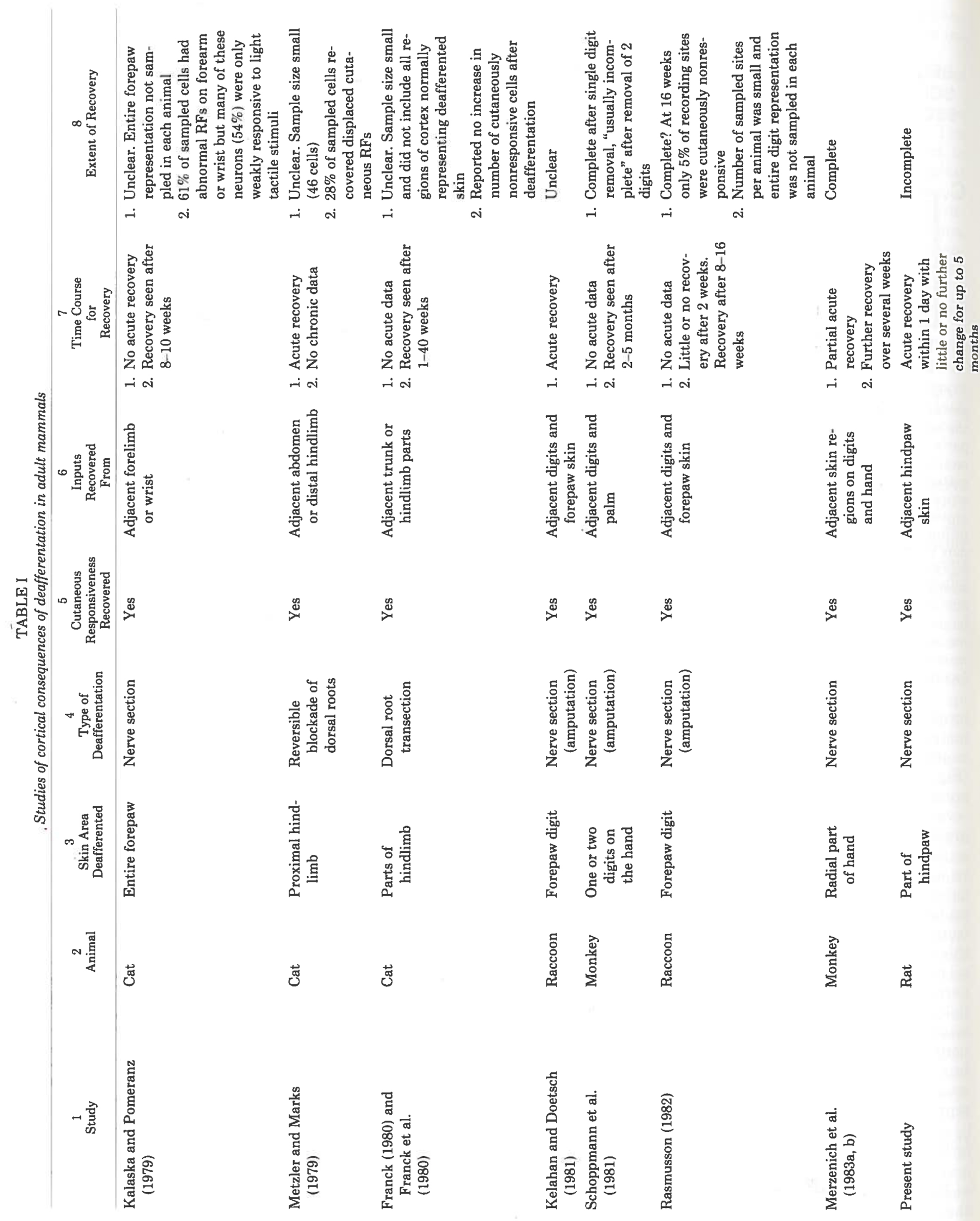


of recovery in previous studies makes detailed comparison with the time course curve of the present study difficult.

4. A second major goal of the present study was to evaluate the extent of recovery after injury. The main finding is that cutaneous responsiveness is only incompletely recovered in the affected cortical region after chronic deafferentation of several months. The general impression one gets when reviewing previous findings is that deprived cortical regions recover cutaneous responsiveness to a significant and, perhaps, complete extent. Few or no areas appear to remain cutanecusly unresponsive. However, the primary concern of most previous studies was to document how receptive field characteristics of cortical neurons change after deafferentation. For this reason efforts usually have not been made to show: $(a)$ the variability in the size and location of the normal cortical representation of the deafferented skin area, $(b)$ that the entire extent of cortex representing the deafferented skin was sampled in denervated animals, or (c) that sampling was systematic and of sufficient detail to provide a comprehensive evaluation of the deafferented cortex. It is thus usually difficult to judge whether cutaneous responsiveness was recovered throughout the deprived cortex or whether some regions remained unresponsive to cutaneous stimuli (Table I, column 8).

Significant exceptions to this statement are previous studies in monkeys which have used cortical mapping techniques similar to those of the present study in attempts to sample systematically all cortical regions normally representing the deafferented skin. The results from these studies (Schoppmann et al., 1981; Merzenich et al., 1983a, b) suggest that recovery can be either complete or incomplete. When the radial half of the hand was deafferented by transection of the median nerve or when a single digit on the hand was amputated, all deprived cortical areas appeared to recover cutaneous responsiveness. However, following amputation of two digits, recovery was sometimes more limited. Considered with the present results, it seems reasonable to conclude that the extent of cortical recovery may vary.

The factors which determine whether cutaneous inputs are recovered are not clear, currently, but the following possibilities might be suggested. (a) The size of the deafferented skin zone may be important. (b) If the hypothesis suggested in Figure 13 is correct, a second factor may be the size of the central convergence zones from adjacent cutaneous inputs and the capacity of the somatosensory system to adjust the dominance of the inputs to these possible "expansion" areas. (c) Changes in the use of skin regions which are adjacent to deafferented skin zones may be important. For example, an increase in the use of these skin areas may serve an important role in adjusting dominance of inputs to expansion areas of cortex. (d) Substitution of noncutaneous inputs may occur. This possibility was not examined in the present experiments because responsiveness of cells was tested only with tactile stimuli. In the case of the hindpaw representation, one might suggest a number of possible sources of "noncutaneous" input. For example, recent findings suggest that sensory and motor functions may overlap in the S-I representation of the hindlimb in rats (Hall and Lindholm, 1974; Donoghue et al., 1979; Sapienza et al., 1981). It seems plausible that parts of the hindpaw representation may receive substitute inputs from the "motor system" following sensory input loss. A second possibility is that substitute inputs may come from other cortical regions. For example, Akers and Killackey (1978) have demonstrated heavy callosal projections to agranular cortical zones bordering S-I granular cortex. There are, of course, other possibilities; however, it currently is unclear whether such inputs can effectively "outcompete" surviving cutaneous inputs for cortical space.

\section{Subcortical effects of deafferentation and their relation to cortical changes}

Deafferentation has also been shown to change cutaneous responsiveness in subcortical structures of adult mammals, and the changes are similar in several respects to those described in the present study. For example, it has been reported that: (a) substitute cutaneous inputs from skin regions bordering deafferented skin can be recovered in parts of the dorsal horn or nucleus gracilis which would normally represent the deafferented skin region (Basbaum and Wall, 1976; Dostrovsky et al., 1976; Millar et al., 1976; Devor and Wall, 1978, 1981a, b; Mendell et al., 1978; Pubols, 1982), (b) recovery can be seen soon after injury (Dostrovsky et al., 1976; Millar et al., 1976) and following more prolonged deafferentation (Basbaum and Wall, 1976; Dostrovsky et al., 1976; Devor and Wall, 1978; Mendell et al., 1978; Pubols and Goldberger, 1980; Pubols, 1982), and (c) cutaneous responsiveness sometimes appeared to be incompletely recovered in deprived regions of subcortical structures (Basbaum and Wall, 1976; Dostrovsky et al., 1976; Millar et al., 1976; Mendell et al., 1978; Devor and Wall, 1981b; Pubols, 1982; Pubols and Brenowitz, 1982).

In view of these similarities between cortical and subcortical changes, an important question is, do changes seen at cortex occur in cortex, in subcortical relays, or all along the skin to the cortex system? From the above evidence it is likely that subcortical changes contribute to cortical reorganization, but it seems premature to attribute all deafferentation changes to subcortical structures. It may be possible to resolve this issue by studying subcortical and cortical deafferentation effects in the same animal.

\section{Are rapidly developed cortical deafferentation effects related to more general changes which occur normally?}

Under normal conditions the sciatic nerve very likely plays a dominant role in transmission of cutaneous information from the hindpaw in that it innervates most of the hindpaw and its inputs activate most of the cortical representation of the hindpaw. Following sciatic transection, most of the hindpaw skin loses its low threshold inputs and all sensory functions from the hindpaw skin must be served by saphenous inputs. Saphenous inputs would appear to take on increased functional importance and, perhaps, would be used differently or to a greater 
extent after deafferentation. The rapid time course for expansion of the cortical representation of saphenous inputs suggests that pre-existing connections undergo functional alterations, and it may be that the enlarged saphenous representation represents one extreme of how cortical space can be delegated or used in a normal adult rat. If this reasoning is correct, inputs which converge onto central neurons (e.g., inputs converging from different skin locations via separate nerves) may normally be organized in terms of their dominance in driving these neurons, but this dominance may be modifiable as a function of input changes. Several investigators have previously concluded that functional factors are important for cortical change after nerve injury or blockade (Metzler and Marks, 1979; Franck, 1980; Kelahan and Doetsch, 1981; Merzenich and Kaas, 1982; Merzenich et al., $1983 \mathrm{~b}$ ), and it is relatively easy to imagine the changes expressed in "expansion" cortex (Fig. 13D) as being related to mechanisms of functional change which have been hypothesized previously (Merrill and Wall, 1978) to underly switching of central connections after nerve injury.

Other observations from studies of central sensory systems appear to be consistent with this view. First, a considerable amount of evidence suggests that normal functional properties such as receptive field location or receptive field size do not fully reflect the wider range of inputs available to sensory neurons (Merrill and Wall, 1972; Wall and Werman, 1976; Devor et al., 1977; Dostrovsky et al., 1977; Mendell et al., 1978). Thus, all inputs converging on a cortical or other central neuron are not equally successful in activating the neuron under normal conditions. Sensory systems may take advantage of less dominant inputs to maintain some degree of functional plasticity in connections. Second, a number of studies have shown that responsiveness of central sensory neurons can be modified as a function of sensory use during learning (Groves and Thompson, 1973; Oleson et al., 1975; Woody et al., 1976; Gibbs and Cohen, 1980; Wall et al., 1980b; Disterhoff et al., 1982; Weinberger, 1982). These response modifications can be highly specific and can be developed rapidly. Increases in the response strength of preferentially used inputs can also result in enlargement of the cortical representation for these inputs (Spinelli and Jensen, 1979; Metzler, 1980).

Thus, it is conceivable that deafferentation may change the relative use of injured and intact inputs and bring about changes which are similar to normal learning or use-related changes. This suggests that sensory system changes due to use or learning may also have limitations, central spatial distribution characteristics, or substitution rules like those described in the present study. This possibility has not been tested in learning studies of sensory neurons because stimuli used in these studies generally have not been related to the central representations of different nerve inputs.

\section{Substitution of cutaneous inputs after nerve injury and subsequent central recovery after nerve regeneration}

Peripheral deafferentation results in loss of tactile sensitivity in the denervated skin zone and, in the absence of central substitution, in loss of cutaneous responsiveness for neurons in the central representations of injured inputs. If the normal function of cortical neurons involves monitoring or interpreting skin inputs, prolonged loss of these inputs might diminish, perhaps irreversibly, the functional capacities of these neurons. This loss of central function would seem unfortunate in view of the regeneration abilities of injured peripheral nerves. It thus seems plausible that substitution may serve a useful role in keeping central neurons "cutaneously active" while regeneration of injured nerves reestablishes peripheral inputs. In that alternate inputs come from skin areas which are adjacent to denervated skin, there is no serious central confusion of inputs during this period. Interesting in this respect is that cutaneous substitutions occurring after nerve injury are themselves progressively replaced by inputs from the injured nerve as this nerve regenerates (Wall et al., 1980a, 1982, 1983). Substitution thus represents only one stage in recovery of cortical function after nerve injury.

\section{References}

Akers, R. M., and H. P. Killackey (1978) Organization of corticocortical connections in the parietal cortex of the rat. J. Comp. Neurol. 181: 513-538.

Basbaum, A. I., and P. D. Wall (1976) Chronic changes in the response of cells in adult cat dorsal horn following partial deafferentation: The appearance of responding cells in a previously non-responsive region. Brain Res. 116: 181-204.

Burgess, P. R., J. F. Howe, M. J. Lessler, and D. Whitehorn (1974) Cutaneous receptors supplied by myelinated fibers in the cat. II. Number of mechanoreceptors excited by a local stimulus. J. Neurophysiol. 37: 1373-1386.

Devor, M., and P. D. Wall (1978) Reorganization of spinal cord sensory map after peripheral nerve injury. Nature 276: 7576.

Devor, M., and P. D. Wall (1981a) Plasticity in the spinal cord sensory map following peripheral nerve injury in rats. J. Neurosci. 1: 679-684.

Devor, M., and P. D. Wall (1981b) Effect of peripheral nerve injury on receptive fields of cells in the cat spinal cord. J. Comp. Neurol. 199: 277-291.

Devor, M., E. G. Merrill, and P. D. Wall (1977) Dorsal horn cells that respond to stimulation of distant dorsal roots. J. Physiol. (Lond.) 270: 519-531.

Devor, M., D. Schonfeld, Z. Seltzer, and P. D. Wall (1979) Two modes of cutaneous reinnervation following peripheral nerve injury. J. Comp. Neurol. 185: 211-220.

Diamond, J., and P. C. Jackson (1978) Do cutaneous nerves sprout in the mammal? J. Physiol. (Lond.) 280: 52-53P.

Disterhoff, J. F., M. T. Shipley, and N. Kraus (1982) Analyzing the rabbit NM conditioned reflex arc. In Conditioning, C. D. Woody, ed., pp. 433-449, Plenum Press, New York.

Donoghue, J. P., K. L. Kerman, and F. F. Ebner (1979) Evidence for two organizational plans within the somatic sensory-motor cortex of the rat. J. Comp. Neurol. 183: 647-664.

Dostrovsky, J. O., J. Millar, and P. D. Wall (1976) The immediate shift of afferent drive of dorsal column nucleus cells following deafferentation: A comparison of acute and chronic deafferentation in gracile nucleus and spinal cord. Exp. Neurol. 52: $480-495$.

Dostrovsky, J. O., S. Jabbur, and J. Miller (1977) Anomalous connections in cat gracile nucleus. J. Physiol. (Lond.) 272 : $38-39 \mathrm{P}$

Franck, J. I. (1980) Functional reorganization of cat somatic sensory-motor cortex (SmI) after selective dorsal root rhizotomies. Brain Res. 186: 458-462.

Franck, J. I., J. Metzler, and P. S. Marks (1980) Chronic 
changes in cat somatic sensory-motor cortex ( $\mathrm{SmI}$ ) following selective dorsal root section. Soc. Neurosci. Abstr. 6: 62 .

Gibbs, C. M., and D. H. Cohen (1980) Plasticity of the thalamofugal pathway during visual conditioning. Soc. Neurosci. Abstr. 6: 424.

Groves, P. M., and R. F. Thompson (1973) A dual process theory of habituation: Neural mechanisms. In Habituation: Physiological Substrates, H. V. S. Peeke and M. J. Herz, eds., Vol. II, pp. 175-205, Academic Press, Inc., New York.

Hall, R. D., and E. P. Lindholm (1974) Organization of motor and somatosensory neocortex in the albino rat. Brain Res. 66: $23-38$.

Horch, K. (1981) Absence of functional collateral sprouting of mechanoreceptor axons into denervated areas of mammalian skin. Exp. Neurol. 74: 313-317.

Jackson, P. C., and J. Diamond (1981) Regenerating axons reclaim sensory targets from collateral nerve sprouts. Science 214: 926-928.

Kaas, J. H., M. M. Merzenich, and H. P. Killackey (1983) The reorganization of somatosensory cortex following peripheral nerve damage in adult and developing mammals. Annu. Rev. Neurosci. 6: 325-356.

Kalaska, J., and B. Pomeranz (1979) Chronic paw denervation causes an age-dependent appearance of novel responses from forearm in "paw cortex" of kittens and adult cats. J. Neurophysiol. 42: 618-633.

Kelahan, A. M., and G. S. Doetsch (1981) Short-term changes in the functional organization of somatosensory (SmI) cortex of adult raccoons after digit amputation. Soc. Neurosci. Abstr. 7: 540.

Kitchell, R. I.., D. D. Canton, R. D. .Johnson, and S. A. Maxwell (1982) Electrophysiologic studies of cutaneous nerves of the forelimb of the cat. J. Comp. Neurol. 210:400-410.

Mendell, L. M., E. M. Sassoon, and P. D. Wall (1978) Properties of synaptic linkage from long ranging afferents onto dorsal horn neurones in normal deafferented cats. J. Physiol. (Lond.) 285: 299-310.

Merrill, E. G., and P. D. Wall (1972) Factors forming the edge of a receptive field: The presence of relatively ineffective afferent terminals. J. Physiol. (Lond.) 226: 825-846.

Merrill, E. G., and P. D. Wall (1978) Plasticity of connection in the adult nervous system. In Neuronal Plasticity, C. W. Cotman, ed., pp. 97-111, Raven Press, New York.

Merzenich, M. M., and J. H. Kaas (1982) Reorganization of mammalian somatosensory cortex following peripheral nerve injury. Trends Neurosci. 5: 434-436.

Merzenich, M. M., J. H. Kaas, M. Sur, and C. -S. Lin (1978) Double representation of the body surface within cytoarchitectonic areas $3 \mathrm{~b}$ and 1 in "SI" in the owl monkey (Aotus trivirgatus). J. Comp. Neurol. 181: 41-74.

Merzenich, M. M., J. H. Kaas, J. Wall, R. J. Nelson, M. Sur, and D. Felleman (1983a) Topographic reorganization of somatosensory cortical areas $3 \mathrm{~b}$ and 1 in adult monkeys following restricted deafferentation. Neuroscience 8: 33-55.

Merzenich, M. M., J. H. Kaas, J. T. Wall, M. Sur, R. J. Nelson, and D. J. Felleman (1983b) Progression of change following median nerve section in the cortical representation of the hand in areas $3 \mathrm{~b}$ and 1 in adult owl and squirrel monkeys. Neuroscience 10:639 665 .

Metzler, J. (1980) Functional reorganization and sensory interactions in cat somatic sensory-motor and striate cortex. Soc. Neurosci. Abstr. 6: 638.

Metzler, J., and P. S. Marks (1979) Functional changes in cat somatic sensory-motor cortex during short term reversible epidural blocks. Brain Res. 177: 379-383.

Millar, J., A. I. Basbaum, and P. D. Wall (1976) Restructuring of the somatotopic map and appearance of abnormal neuronal activity in the gracile nucleus after partial deafferentation. Exp. Neurol. 50: 658-672.

Oleson, T. D., J. H. Ashe, and N. M. Weinberger (1975) Modification of auditory and somatosensory system activity during pupillary conditioning in the paralyzed cat. J. Neurophysiol. 38: 1114-1139.

Pubols, L. M. (1982) Response properties and somatic organization of dorsal horn neurons following nerve lesions in the cat. Soc. Neurosci. Abstr. 8: 141.

Pubols, L. M., and G. L. Brenowitz (1982) Maintenance of dorsal horn somatotopic organization and increased highthreshold response after single-root or spared-root deafferentation in cats. J. Neurophysiol. 47: 103-112.

Pubols, L. M., and M. E. Goldberger (1980) Recovery of function in dorsal horn following partial deafferentation. J. Neurophysiol. 43 : $102-117$.

Rasmusson, D. D. (1982) Reorganization of raccoon somatosensory cortex following removal of the fifth digit. J. Comp. Neurol. 205: 313-326.

Sapienza, S., B. Talbi, J. Jacquemin, and D. Albe-Fessard (1981) Relationship between input and output of cells in motor and somatosensory cortices of the chronic awake rat. Exp. Brain Res. 43: 47-56.

Schoppmann, A., R. J. Nelson, M. P. Stryker, M. Cynader, J. Zook, and M. M. Merzenich (1981) Reorganization of hand representation within area $3 \mathrm{~b}$ following digit amputation in owl monkey. Soc. Neurosci. Abstr. 7: 842.

Spinelli, D. N., and F. E. Jensen (1979) Plasticity: The mirror of experience. Science 203: 75-78.

Wall, J. T., M. M. Merzenich, M. Sur, R. J. Nelson, D. J. Felleman, and J. H. Kaas (1980a) Organization of the representations of the hand in areas $3 \mathrm{~b}$ and 1 of postcentral somatosensory cortex of monkeys after section and regeneration of the median nerve. Soc. Neurosci. Abstr. 6: 651 .

Wall, J. T., e. M. Wild, J. Broyles, C. M. Gibbs, and D. H. Cohen (1980b) Plasticity of the tectofugal pathway during visual conditioning. Soc. Neurosci. Abstr. 6: 424.

Wall, J. T., D. J. Felleman, and J. H. Kaas (1982) Effects of median nerve crush and regeneration on the organization of the hand representation in area $3 b$ of monkeys. Soc. Neurosci. Abstr. 8: 851.

Wall, J. T., D. J. Felleman, and J. H. Kaas (1983) Recovery of normal topography in the somatosensory cortex of monkeys after nerve crush and regeneration. Science 221: 771-773.

Wall, P. D., and R. Werman (1976) The physiology and anatomy of long ranging afferent fibers within the spinal cord. J. Physiol. (Lond.) 255: 321-334.

Weinberger, N. M. (1982) Sensory plasticity and learning: The magnocellular medial geniculate nucleus of the auditory system. In Conditioning, C. D. Woody, Ed., pp. 697-710, Plenum Press, New York.

Welker, C. (1971) Microelectrode delineation of fine grain somatotopic organization of SmI cerebral neocortex in albino rat. Brain Res. 26: 259-275.

Welker, C. (1976) Receptive fields of barrels in the somatosensory neocortex of the rat. J. Comp. Neurol. 166: 173-190.

Woody, C. D., J. D. Knispel, T. J. Crow, and P. A. BlackCleworth (1976) Activity and excitability to electric current of cortical auditory receptive neurons of awake cats as affected by stimulus association. J. Neurophysiol. 39: 10451061.

Woolsey, C. N. (1958) Organization of somatic sensory and motor areas of the cerebral cortex. In Biological and Biochemical Bases of Behavior, H. F. Harlow and C. N. Woolsey, eds., pp. 63-81, University of Wisconsin Press, Madison. 